\title{
Living with a Brain AVM: A Quality of Life Assessment
}

\author{
Péter Orosz, Ágnes Vadász, Dániel Sándor Veres, \\ Zsolt Berentei, István Gubucz, Sándor Nardai, Balázs Kis, \\ and István Szikora
}

\section{Introduction}

Arteriovenous malformations (AVM) are considered to be sporadic congenital vascular lesions, consisting of abnormal blood vessels forming direct connections between arteries and veins without capillary network. Brain AVMs affect $0.1 \%$ of the population [1] with an incidence of 1.3 per 100,000 persons a year [2]. Cerebral AVMs can be asymptomatic, but when they are symptomatic, patients can present with intracranial hemorrhage (ICH), seizures, neurological deficits, and headache [3, 4]. The most frequent presenting symptom is ICH, detected in 50\% of cases [4]. Hemorrhages are usually intraparenchymal, but subarachnoid location is also common: brain AVMs are responsible for 9\% of subarachnoid hemorrhages [5] and represents the leading cause of ICH in young adults [4]. The overall annual rupture risk was reported to be $2.3-3 \%, 1.3-2.2 \%$ for unruptured, and $4.5-4.8 \%$ for ruptured cases respectively $[4,6]$. Patients with a history of ruptured AVM are at higher risk of hemorrhage than those without it. Seizures are present in $11-33 \%$ of cases [7]. The 5-year seizure risk for asymptomatic patients with AVM is $8 \%$, although when presenting with ICH or focal neurologic deficits the same risk rises to $23 \%$ [8]. Headache was reported to be associated with cerebral AVM in $17-50 \%$ of cases [9], while neurological deficits may be present in 3-10\% [10]. Mortality rates range between $0.7 \%$ and $2.9 \%$ per year [11].

Treatment options include conservative therapy, neurosurgical elimination, radiosurgery, endovascular techniques, and combinations of these options. The therapeutic approach

P. Orosz $(\bowtie) \cdot$ Á. Vadász $\cdot$ Z. Berentei $\cdot$ I. Gubucz $\cdot$ S. Nardai B. Kis · I. Szikora

National Institute of Clinical Neurosciences, Budapest, Hungary e-mail: h13424szi@ella.hu

D. S. Veres

Department of Biophysics and Radiation Biology, Semmelweis

University, Budapest, Hungary

e-mail: veres.daniel@med.semmelweis-univ.hu to AVMs is controversial. Only one randomized controlled trial was published in the literature on the management of unruptured AVMs. According to the findings of the ARUBA trial it is suggested not to perform interventional treatment in such cases due to worse clinical outcome compared to those cases with medical treatment alone [12]. Many authors are arguing with these results due to their professional experience, controversial results of other reports, and the main limitations of the trial: application of a variety of treatment modalities without specifying the selection strategy, inclusion of a variety of different size and type of AMVs, and the short follow-up period $[13,14]$. Nevertheless, the results of the non-randomized Scottish Audit of Intracranial Vascular Malformation with a follow-up of 12 years also supports the findings of the ARUBA trial [15]. Altogether because of the lack of evidence-based guidelines for management options, the therapeutic approach is highly individual, should be multidisciplinary, and has to be based on as much information as possible. According to the ARUBA trial, as well as in clinical practice, the primary consideration for decision-making in cases with untreated AVMs is the risk of hemorrhage, disability and mortality $[13,15,16]$. The impact of an untreated AVM on the quality of life (QOL) is generally not considered. Reports on outcome regarding QOL are uncommon in the literature, with most of the publications not focusing on cases with untreated AVM [17, 18], although disability doesn't always correlate with the QOL. Therefore, its assessment can provide important additional information for therapeutic decisions. The application of QOL assessment is increasingly accepted as a major endpoint in clinical trials and has a more important role in decision-making in neurosurgical practice as well $[19,20]$. Hereby we report our observational results of patients with brain AVM without interventional treatment based on their QOL. 


\section{Methods and Materials}

Twenty female and 16 male patients were enrolled in our study with a mean age of $45 \pm 16$ years. Subjects were identified retrospectively from the AVM database of our hospital. Patients with unruptured cerebral AVM without interventional treatment over the age of 18 met our inclusion criteria. We excluded patients with other intracranial pathology potentially responsible for the symptoms. The AVMs were detected between 2000 and 2018. All patients have visited either the outpatient or the inpatient ward of the National Institute of Clinical Neurosciences in Budapest, where the diagnosis of AVM was either made or confirmed. After physical examination, AVM was detected by either contrast-enhanced computed tomography (CT) or magnetic resonance imaging (MRI). Digital subtraction angiography (DSA) was performed for precise characterization of the AVM in each case. Treatment decision (conservative or invasive) was made by the patient or chosen individually by the treatment team.

We used the standardized EQ-5D-5L questionnaire for measuring the QOL [21]. It was designed by the EuroQol Group to estimate the patient's health-related state with the help of a descriptive system and a visual analogue scale (VAS). The EQ-5D-5L descriptive system consists of a 5-level scale (according to the severity of symptoms) in five dimensions (mobility, self-care, usual activity, pain/discomfort and anxiety/depression). The VAS registers the patient's actual level of general health on a scale from 0 to 100 , assuming 0 as the worst and 100 as the best imaginable health state. Our subjects were interviewed by telephone in 2018 retrospectively. No previous QOL tests were performed in their cases prior to our study.

As a control group we used the results of the Research Report (RR) of the National Health Survey from 2002 [22]. This Hungarian nationwide report used the EQ-5D-3L questionnaire [23] to measure the QOL on a cohort of 5534 healthy subjects. This questionnaire was also designed by the EuroQol Group as a less sensitive tool than the EQ-5D-5L version; it uses a 3-level scale instead of 5 in case of every dimension of the descriptive system. Level 1 is chosen if the subject doesn't have any problem in the designated dimension, Level 2 if there is some trouble regarding the category, and Level 3 if severe impairment is present. The EQ-5D-3L descriptive system results of the RR were categorized in two groups for statistical analysis in every dimension: the first group contained the answers of Level 1, while Levels 2 and 3 represented the second group. To facilitate an adequate comparison we categorized our results likewise: the first group represented patients with no complaint (Level 1) and subjects with any complaint (Level 2-5) became the members of the second group. The aforementioned RR discussed their findings in three age groups (18-34, 35-64 and older than 65) and considered females and males separately. We, therefore, made the same subdivisions. The RR summarized their findings on VAS as well, though they were not reported by age groups; therefore, we lacked data for adequate comparison.

We compared the results of the descriptive system of the RR with our findings, but statistical analysis wasn't made due to the small number of our subjects. For illustrating our results, we prepared diagrams to demonstrate the numeric differences between the two groups. Our observations on the VAS were also provided in details and demonstrated visually, but we missed data for comparison.

The study was approved by the Institutional Committee of Science and Research Ethics of the National Institute of Clinical Neurosciences. All participants gave written informed consent of participation.

\section{Results}

Thirty-six patients ( $n=20$ female and $n=16$ male) met our inclusion criteria with a mean age of $45 \pm 16$ years. Their average follow-up time was $57.4 \pm 49$ months. Headache was present in 15 patients with a female predominance ( $n=12$ female and $n=3$ male), thus proving to be the most common AVM-related sign in our cohort (41.6\%). Epileptic seizures occurred in nine cases $(25 \%)$, more commonly affecting male subjects ( $n=7$ male and $n=2$ female). Neurological deficit was detected in $33 \%$ of our cohort ( $n=12 ; n=8$ female and $n=4$ male). Table 1 shows the patient characteristics.

\section{Results of the EQ-5D-5L Descriptive System}

\section{Mobility}

We observed a tendency toward decrease in the mobility of our female subjects by age, which occurred also in the control population, but less frequently. Although we expected the same tendency for men, older male subjects proved not to

Table 1 Patient characteristics. Division by the sex of the patients

\begin{tabular}{|c|c|c|c|}
\hline & Female $(n)$ & Male $(n)$ & All $(n ; \%)$ \\
\hline \multicolumn{4}{|l|}{ Age } \\
\hline $18-34$ & 6 & 5 & $11(30.5 \%)$ \\
\hline $35-64$ & 10 & 8 & $18(50 \%)$ \\
\hline$>65$ & 4 & 3 & $7(19.5 \%)$ \\
\hline \multicolumn{4}{|l|}{ Symptoms } \\
\hline headache & 12 & 3 & $41.6(40 \%)$ \\
\hline epileptic seizures & 2 & 7 & $9(25 \%)$ \\
\hline neurological deficit & 8 & 4 & $12(33 \%)$ \\
\hline
\end{tabular}




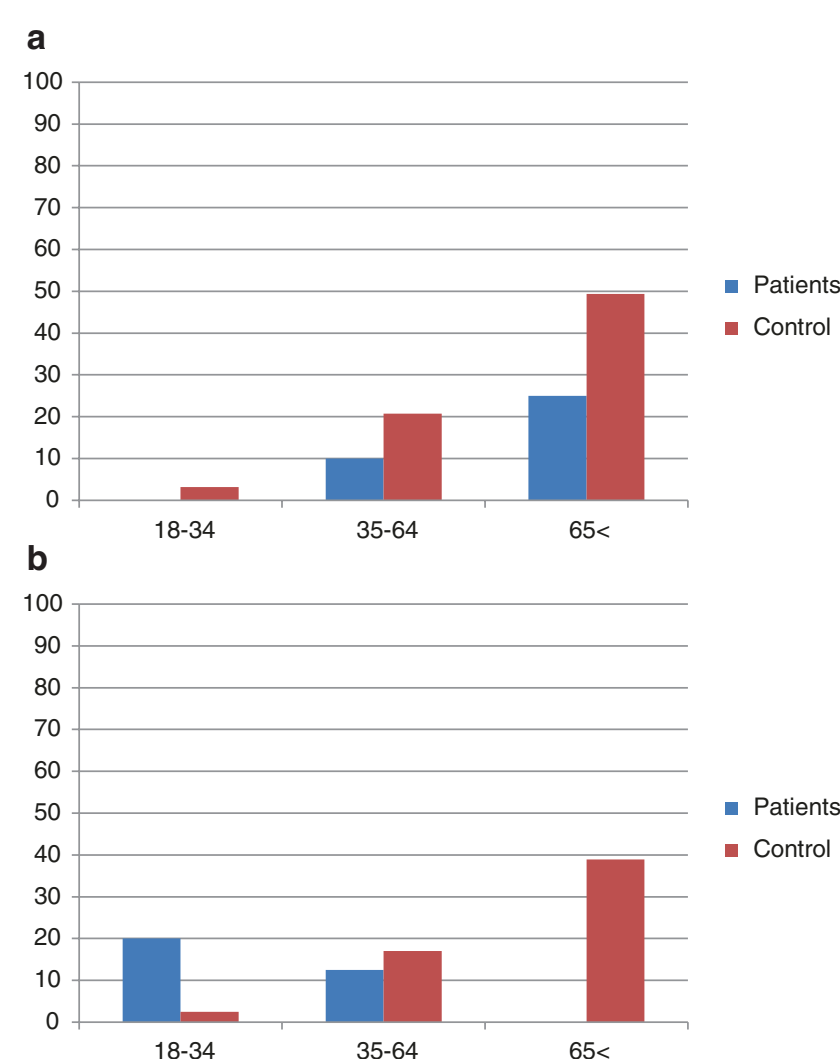

Fig. 1 (a) Female mobility impairment according to age groups in our patients (blue columns) compared to the control cohort (red columns). (b). Male mobility impairment according to age groups in our patients (blue columns) compared to the control cohort (red columns)

have any problem in this regard, middle-aged patients had less complaint than the subjects of the RR, and young males showed significantly more severe impairment in their mobility compared with the control group (we observed an eightfold difference) (Fig. 1).

\section{Self-Care}

Although the results of the RR show an increasing impairment by age in the question of self-care, our female subjects and younger male patients proved not to be limited by this factor. In case of our male subjects older than 65 years of age, we observed a severe impairment in comparison with the control group (twofold difference) (Fig. 2).

\section{Usual Activity}

Decline in usual activity showed a male dominance in our cohort. The most significant difference between the control group and our patients was seen in the case of young (22-fold difference) and middle-aged males (2.8-fold difference). Only middle-aged female subjects exceeded their healthy controls. Altogether usual activity impairment seems to be a more limiting factor in male patients under the age of 65 years (Fig. 3).

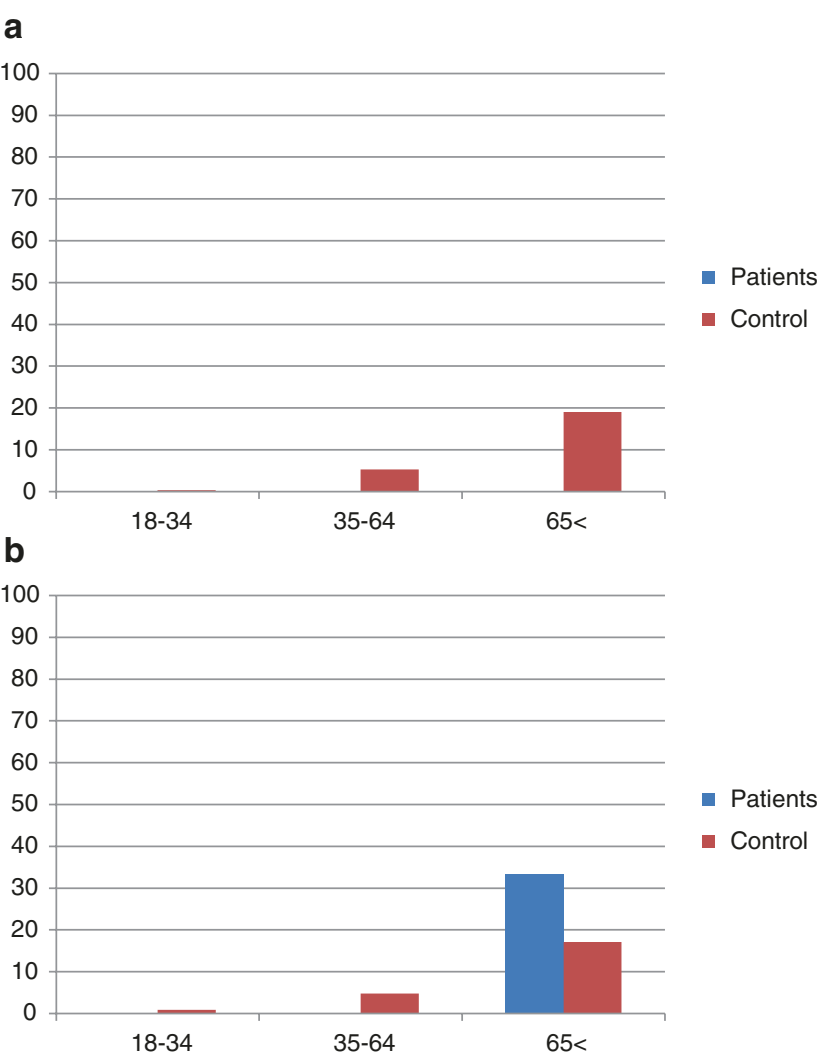

Fig. 2 (a) Female self-care impairment according to age groups in our patients (blue columns) compared to the control cohort (red columns). (b) Male self-care impairment according to age groups in our patients (blue columns) compared to the control cohort (red columns)

\section{Pain and Discomfort}

Pain and discomfort have an increasing impact on the QOL of the general population by age according to the results of the RR. Women are affected more frequently in all age groups compared with male subjects. Our patients demonstrated a different behavior. Young women (18-34 years) exceeded by 3.6-fold the level of their healthy controls, while female subjects older than 35 years of age stayed below the level of the control group. Middle-aged male patients also surpassed the control males by 1.4. The greatest difference (fourfold) was seen in case of young male subjects (1834 years). In conclusion, cerebral AVM has the most remarkable effect on pain and discomfort in case of young patients, especially in male subjects (Fig. 4).

\section{Anxiety and Depression}

Very similarly to the pain and discomfort results we found anxiety and depression to affect young patients (18-34 years) the most, surpassing the RR population. Eighty percent of men and $50 \%$ of women of the youngest age group answered that anxiety and depression were important factors in their lives due to their diagnosed AVM. Different sex ratios, however, were found: 2 for female and 5.3 for male patients. 


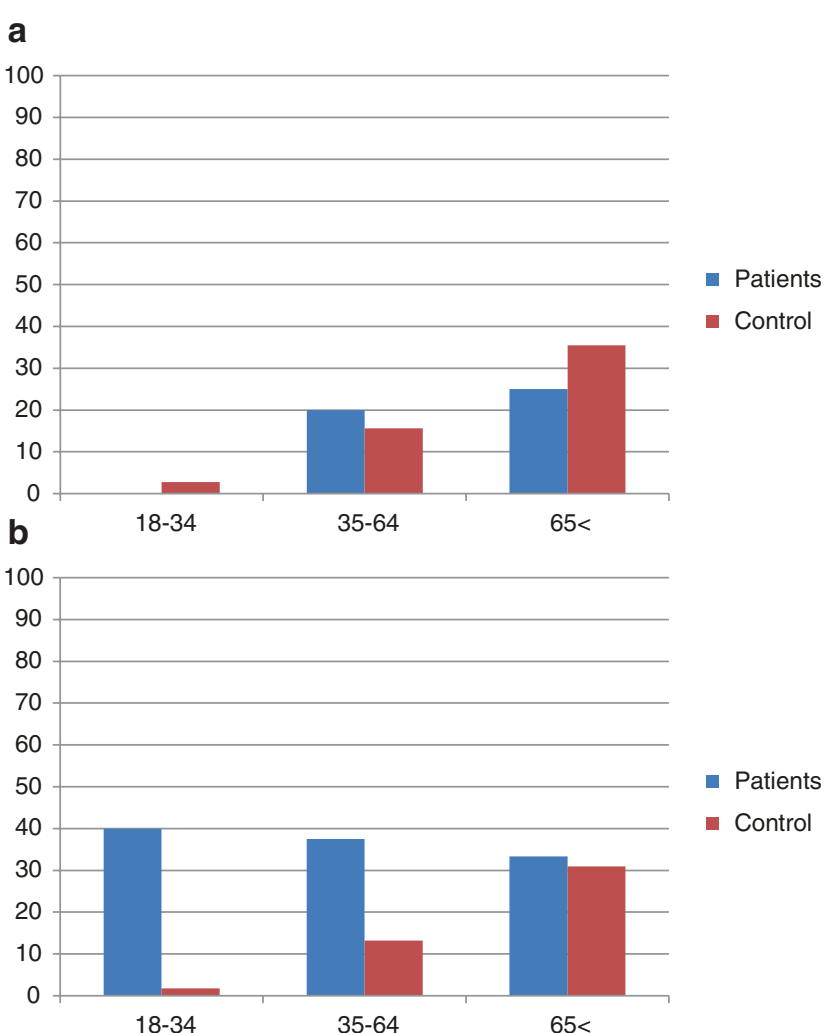

Fig. 3 (a) Female usual activity decline according to age groups in our patients (blue columns) compared to the control cohort (red columns). (b) Male usual activity decline according to age groups in our patients (blue columns) compared to the control cohort (red columns)

Middle-aged males also surpassed the control group, but only with a 1.25 -fold difference. In conclusion, brain AVM also has a significant effect on anxiety and depression with a male predominance in case of younger patients (Fig. 5).

\section{Impact of the Different Factors on QOL}

We found that anxiety/depression and pain/discomfort are the most significant factors influencing the QOL in our cohort (47.2\% and $41.6 \%$ respectively). Twenty-five percent of our patients responded that they had troubles in performing their usual activities, while mobility and self-care were affected less frequently (11\% and 2.7\% respectively) (Fig. 6).

\section{Results of the EQ-5D-5L VAS}

The mean result of the VAS in our cohort was proved to be $84.6 \pm 22$ points. According to age groups, the youngest and middle-aged patients were found similar (83\% and $86 \%$ ), while older subjects rated themselves to a lower level (70\%). Forty-four percent of our cases rated themselves above 95 points, while $30.5 \%$ of them considered their actual level of general health less than 80 points. The RR findings on VAS

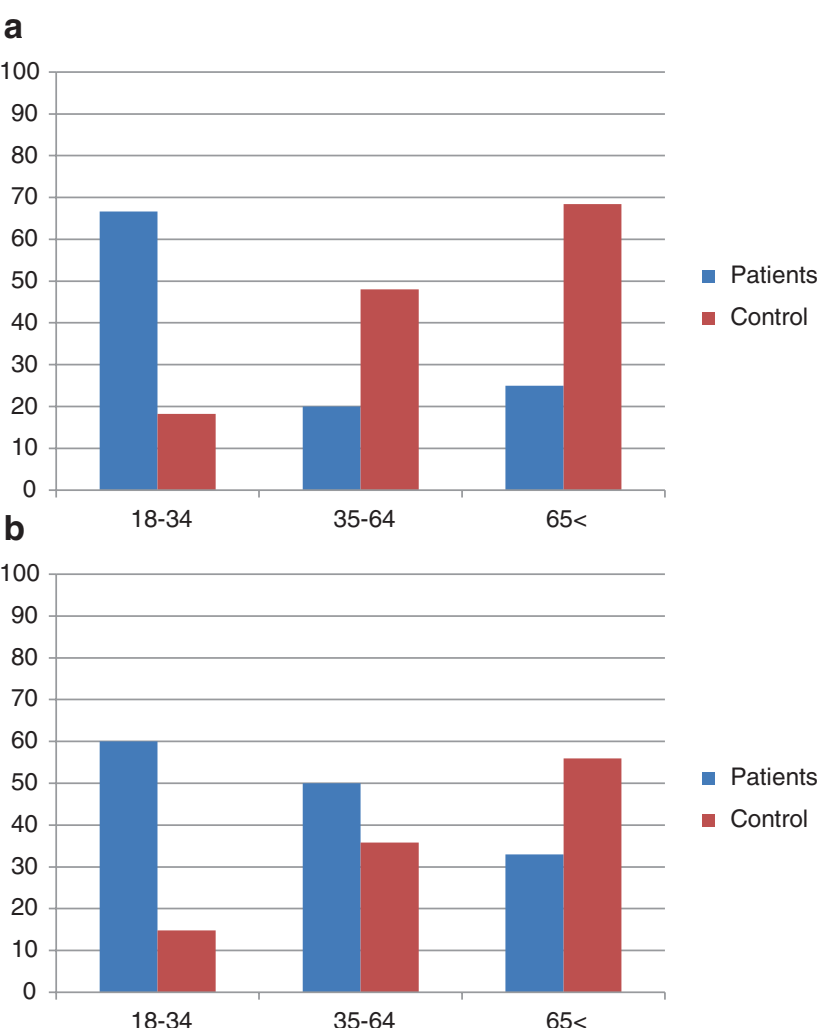

Fig. 4 (a) Female frequency of pain and discomfort according to age groups in our patients (blue columns) compared to the control cohort (red columns). (b) Male frequency of pain and discomfort according to age groups in our patients (blue columns) compared to the control cohort (red columns)

were not reported by age group; therefore we lack data for comparison (Table 2).

\section{Discussion}

Untreated unruptured brain AVMs do have an impact on the QOL. Due to the judgement of more than $30 \%$ of our subjects, living with cerebral AVM represents a significant limitation in their QOL. Multiple conditions are responsible for the decreased level of health, but anxiety, depression, pain, and discomfort seem to be the most common influencing factors, especially in young male subjects. Female patients with untreated AVMs demonstrate a greater dependence than men in all age groups. Males with a predominance of young age have a more significant impairment in their usual activities when compared to women. Older patients are affected more significantly in their self-care, while the impact of discomfort and anxiety is more severe in the younger population. The impairment of mobility was seen to surpass significantly the healthy controls in case of young men. 


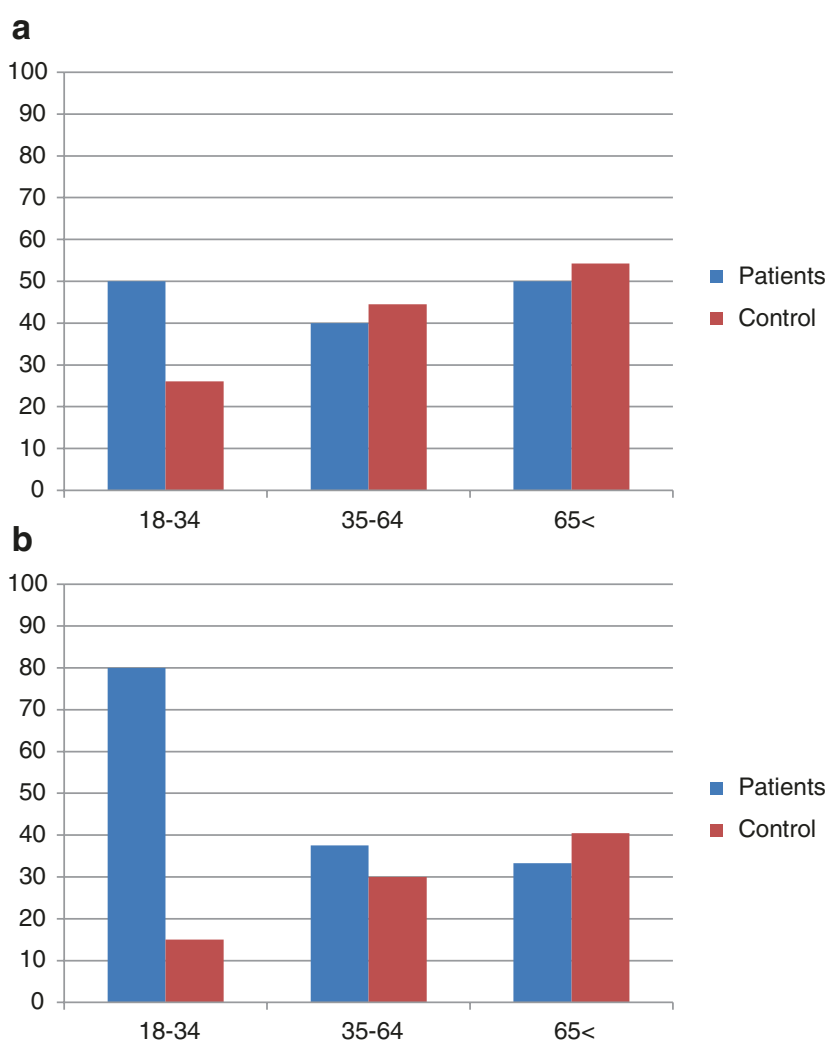

Fig. 5 (a) Female frequency of anxiety and depression according to age groups in our patients (blue columns) compared to the control cohort (red columns). (b) Male frequency of anxiety and depression according to age groups in our patients (blue columns) compared to the control cohort (red columns)

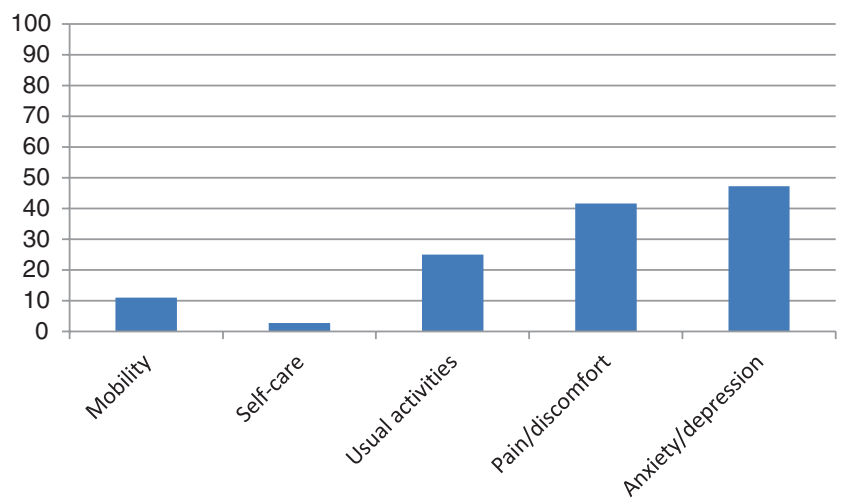

Fig. 6 Impact of the different factors on the QOL in our cohort

Table 2 The VAS results of our cohort by age groups. Male and female subjects are discussed separately

\begin{tabular}{l|l|l}
\hline Age & Female (\%) & Male (\%) \\
\hline $18-34$ & 86.7 & 78.8 \\
\hline $35-64$ & 88.5 & 84.6 \\
\hline $65<$ & 78.8 & 58 \\
\hline
\end{tabular}

In summary, untreated cerebral AVMs seem to have the most demonstrative impact on young male patients, although the limiting factors are highly individual. QOL assessment is, therefore, an important tool and needs to be considered in the therapeutic decision-making in patients with brain AVM. Future studies are necessary to confirm our findings.

The main limitation of our study is the low number of cases, especially in the subgroup calculations, so compelling statistical analysis could not be done when comparing with the control group. Another weakness is the high scatter in the follow-up time and the time between the diagnosis and QOL assessment. Further investigations are needed with larger cohorts and longer follow-up times, though the rarity of the disease represents a great limiting factor.

The strength of our study is the demonstration of the outcome of QOL in the natural course of the disease focusing on purely untreated cases.

Acknowledgements The authors thank all collaborators of this study who have taken part.

\section{Compliance with Ethical Standards}

Conflict of Interest The authors declare no financial or other conflicts of interest.

Ethical Approval The study was approved by the Institutional Committee of Science and Research Ethics of the National Institute of Clinical Neurosciences and it have been performed in accordance with the ethical standards as laid down in the 1964 Declaration of Helsinki and its later amendments or comparable ethical standards.

Informed Consent Informed consent was obtained from all individual participants included in the study.

\section{References}

1. Mohr JP, Kejda-Scharler J, Pile-Spellman J (2013) Diagnosis and treatment of arteriovenous malformations. Curr Neurol Neurosci Rep 13(2):324

2. Gabriel RA, Kim H, Sidney S, McCulloch CE, Singh V, Johnston SC, Ko NU, Achrol AS, Zaroff JG, Young WL (2010) Ten-year detection rate of brain arteriovenous malformations in a large, multiethnic, defined population. Stroke 41(1):21-26

3. Brown RD Jr, Wiebers DO, Torner JC, O'Fallon WM (1996) Frequency of intracranial hemorrhage as a presenting symptom and subtype analysis: a population-based study of intracranial vascular malformations in Olmsted Country, Minnesota. J Neurosurg 85(1):29-32

4. Kim H, Al-Shahi Salman R, McCulloch CE, Stapf C, Young WL, MARS Coinvestigators (2014) Untreated brain arteriovenous mal- 
formation: patient-level meta-analysis of hemorrhage predictors. Neurology 83(7):590-597

5. Al-Shahi R, Warlow C (2001) A systematic review of the frequency and prognosis of arteriovenous malformations of the brain in adults. Brain 124(Pt 10):1900-1926

6. Gross BA, Du R (2013) Natural history of cerebral arteriovenous malformations: a meta-analysis. J Neurosurg 118(2):437-443

7. Garcin B, Houdart E, Porcher R, Manchon E, Saint-Maurice JP, Bresson D, Stapf C (2012) Epileptic seizures at initial presentation in patients with brain arteriovenous malformation. Neurology 78(9):626-631

8. Josephson CB, Leach JP, Duncan R, Roberts RC, Counsell CE, Al-Shahi Salman R, Scottish Audit of Intracranial Vascular Malformations (SAIVMs) Steering Committee and Collaborators (2011) Seizure risk from cavernous or arteriovenous malformations: prospective population-based study. Neurology 76(18):1548-1554

9. Ellis JA, Mejia Munne JC, Lavine SD, Meyers PM, Connolly ES Jr, Solomon RA (2016) Arteriovenous malformations and headache. J Clin Neurosci 23:38-43

10. Laakso A (2017) Epidemiology and natural history of AVMs. In: Beneš V, Bradac O (eds) Brain arteriovenous malformations: pathogenesis, epidemiology, diagnosis, treatment and outcome. Springer International Publishing AG, Basel, pp 37-49

11. Laakso A, Dashti R, Seppänen J, Juvela S, Väärt K, Niemelä M, Sankila R, Hernesniemi JA (2008) Long-term excess mortality in 623 patients with brain arteriovenous malformations. Neurosurgery 63(2):244-253; discussion 253-5.

12. Mohr JP, Parides MK, Stapf C, Moquete E, Moy CS, Overbey JR, Al-Shahi Salman R, Vicaut E, Young WL, Houdart E, Cordonnier C, Stefani MA, Hartmann A, von Kummer R, Biondi A, Berkefeld J, Klijn CJ, Harkness K, Libman R, Barreau X, Moskowitz AJ, International ARUBA Investigators (2014) Medical management with or without interventional therapy for unruptured brain arteriovenous malformations (ARUBA): a multicentre, non-blinded, randomised trial. Lancet 383(9917):614-621

13. Bervini D, Morgan MK, Ritson EA, Heller G (2014) Surgery for unruptured arteriovenous malformations of the brain is better than conservative management for selected cases: a prospective cohort study. J Neurosurg 121(4):878-890

14. Knopman J, Stieg PE (2014) Management of unruptured brain arteriovenous malformations. Lancet 383(9917):581-583

15. Al-Shahi Salman R, White PM, Counsell CE, du Plessis J, van Beijnum J, Josephson CB, Wilkinson T, Wedderburn CJ, Chandy Z, St George EJ, Sellar RJ, Warlow CP, Scottish Audit of Intracranial Vascular Malformations Collaborators (2014) Outcome after conservative management or intervention for unruptured brain arteriovenous malformations. JAMA 311(16):1661-1669

16. Wedderburn CJ, van Beijnum J, Bhattacharya JJ, Counsell CE, Papanastassiou V, Ritchie V, Roberts RC, Sellar RJ, Warlow CP, Al-Shahi Salman R, SIVMS Collaborators (2008) Outcome after interventional or conservative management of unruptured brain arteriovenous malformations: a prospective, population-based cohort study. Lancet Neurol 7(3):223-230

17. Rohn B, Haenggi D, Etminan N, Kunz M, Turowski B, Steiger HJ (2014) Epilepsy, headache, and quality of life after resection of cerebral arteriovenous malformations. J Neurol Surg A Cent Eur Neurosurg 75(4):282-288

18. van der Schaaf IC, Brilstra EH, Rinkel GJ, Bossuyt PM, van Gijn J (2002) Quality of life, anxiety, and depression in patients with an untreated intracranial aneurysm or arteriovenous malformation. Stroke 33(2):440-443

19. Müller-Nordhorn J (2006) Assessing quality of life in clinical trials, 2nd ed. J Epidemiol Community Health 60(9):822

20. Sanchez CE, Ogilvy CS, Carter BS (2007) Outcomes studies in cerebrovascular neurosurgery. Neurosurg Focus 22(3):E11. Review.

21. Herdman M, Gudex C, Lloyd A, Janssen M, Kind P, Parkin D, Bonsel G, Badia X (2011) Development and preliminary testing of the new five-level version of EQ-5D (EQ-5D-5L). Qual Life Res 20(10):1727-1736

22. Julianna B, Renáta N, József V (2002) Kutatási Jelentés. Országos Epidemiológiai Központ, Budapest

23. EuroQol Group (1991) EuroQol--a new facility for the measurement of health-related quality of life. Health Policy 16(3):199-208

Open Access This chapter is licensed under the terms of the Creative Commons Attribution 4.0 International License (http://creativecommons. org/licenses/by/4.0/), which permits use, sharing, adaptation, distribution and reproduction in any medium or format, as long as you give appropriate credit to the original author(s) and the source, provide a link to the Creative Commons license and indicate if changes were made.

The images or other third party material in this chapter are included in the chapter's Creative Commons license, unless indicated otherwise in a credit line to the material. If material is not included in the chapter's Creative Commons license and your intended use is not permitted by statutory regulation or exceeds the permitted use, you will need to obtain permission directly from the copyright holder. 